\title{
New Insights Into the Physiology of Bone Regulation: the Role of Neurohormones
}

\author{
I. ŽOFKOVÁ ${ }^{1}$, P. MATUCHA ${ }^{1}$ \\ ${ }^{1}$ Institute of Endocrinology, Prague, Czech Republic
}

Received September 26, 2013

Accepted January 17, 2014

On-line April 3, 2014

\begin{abstract}
Summary
Bone metabolism is regulated by interaction between two skeletal cells - osteoclasts and osteoblasts. Function of these cells is controlled by a number of humoral factors, including neurohormones, which ensure equilibrium between bone resorption and bone formation. Influence of neurohormones on bone metabolism is often bimodal and depends on the tissue, in which the hormone is expressed. While hypothalamic beta- 1 and beta-2-adrenergic systems stimulate bone formation, beta-2 receptors in bone tissue activate osteoclatogenesis and increases bone resorption. Chronic stimulation of peripheral beta-2 receptors is known to quicken bone loss and alter the mechanical quality of the skeleton. This is supported by the observation of a low incidence of hip fractures in patients treated with betablockers. A bimodal osteo-tropic effect has also been observed with serotonin. While serotonin synthetized in brain has osteo-anabolic effects, serotonin released from the duodenum inhibits osteoblast activity and decreases bone formation. On the other hand, both cannabinoid systems (CB1 receptors in the brain and CB2 in bone tissue) are unambiguously osteoprotective, especially with regard to the aging skeleton. Positive (protective) effects on bone have also been shown by some hypophyseal hormones, such as thyrotropin (which inhibits bone resorption) and adrenocorticotropic hormone and oxytocin, both of which stimulate bone formation. Low oxytocin levels have been shown to potentiate bone loss induced by hypoestrinism in postmenopausal women, as well as in girls with mental anorexia. In addition to reviewing neurohormones with anabolic effects, this article also reviews neurohormones with unambiguously catabolic effects on the skeleton, such as neuropeptide $Y$ and neuromedin $U$. An important aim of research in this field is the
\end{abstract}

synthesis of new molecules that can stimulate osteo-anabolic or inhibiting osteo-catabolic processes.

\section{Key words \\ Bone remodeling - Beta-adrenergic system - Serotonin • Cannabinoids - Melatonin • Oxytocin - Thyrotropin • Adrenocorticotropin}

\section{Corresponding author}

I. Žofková, Institute of Endocrinology, Národní 8, 11694 Prague 1, Czech Republic. E-mail: izofkova@endo.cz; izofkova@upcmail.cz

\section{Introduction}

Recent research has provided strong evidence of interactions between the nervous system and the skeletal system. Specific receptors, associated with bone cells have been identified, which are targeted by many hormones sythetized in brain (Khor et al. 2012). Serotonin, neuropeptide Y (NPY), vasointestinal peptide (VIP), substance P, calcitonin-gene-related peptide (CGRP), norepinephrine and glutamate, all with neural origins, have identifiable effects on bone (Masi et al. 2012). Most new information has come from the effects of the betaadrenergic system (Elefteriou et al. 2014) or serotonin (Kawai et al. 2010) on the skeleton. Studies focused on relationships between bone and neuro-transmitters and hypophyseal hormones have also been published. This review article is focussed on the physiological aspect of specific neuro-skeletal pathways and their potential relative to the treatment of osteoporosis. 


\section{Beta-adrenergic system}

The sympathetic nervous system represents an important physiological linkage between the brain and bone tissue (Elefteriou et al. 2014). Postsynaptic betaadrenergic receptors (coupled to $G$ proteins) are expressed on osteoblasts, where (via cAMP and protein kinase A) they activate phosphorylation of transcription factors controlling osteoblast differentiation and collagen synthesis (Masi et al. 2012). The effect of the betaadrenergic system on the skeleton is bimodal and depends on the type of receptors, which in turn determine the effect. Through the kiss-peptide (regulated by the Kiss-1 gene), beta-1 activates the GnRH-gonadal axis and thereby inhibiting bone resorption. Simultaneously, beta1 increases bone formation (mainly in the periosteum) via activation of the somatotropin-IGF-I axis (Hamrick and Ferrari 2008). This results in beta-1 markedly slowing the bone remodeling process (Bonnet et al. 2008). Osteoanabolic effects have also been observed in the hypothalamic beta-2 system, which inhibits the bone resorption effects of neuropeptide $\mathrm{Y}$ (see below). Central beta-2 agonists stimulate bone formation indirectly through preservation and/or increase in muscle mass (doping effect) (Bonnet et al. 2008). Taken together, the central beta-adrenergic system works as an osteoprotective mechanism. However, the beta- 2 receptors are also expressed in bone tissue, where they activate the osteoclastogenic molecules interleukin 6, interleukin 11 and prostaglandin E2 and subsequently (via PAK and p38 MAPK) bone resorption (Arai et al. 2003, Kondo and Tovaru 2003). It is known, that chronic beta-2 stimulation quickens bone loss and alters the mechanical quality of the skeleton (Bonnet et al. 2008). There are a number of clinical observations that support this theory. Asthmatics treated with beta-2 agonists for a prolonged period of time were found to be at increased risk of femur fractures (de Vries et al. 2007). Farr et al. (2012) studied a group of women aged 20-72 years and demonstrated that high sympathetic activity (bursts per 100 heart beats) was inversely correlated with bone volume and trabecular thickness; moreover in a subgroup of postmenopausal women (taken from the group described above), a negative association was between sympathetic activity and serum amino-terminal propeptide of type I collagen and plasma osteopontin. This agrees with the observation that treatment with beta-blockers inhibits bone resorption, accelerates bone formation in the endosteal and periosteal compartments and increases trabecular thickness in animal experiments (Minkowitz et al. 1991, Bonnet et al. 2008). Gradosova et al. (2011) found that orchidectomized rats treated with metoprolol had high serum IGF-1 levels and slowed metabolic turnover of bone. Similarly, a significant decline in the incidence of hip fractures in patients treated with betablockers has also been observed (Pasco et al. 2004, Schlienger et al. 2004, Bonnet et al. 2008). The above mentioned data are promising from the point of prevention and treatment of osteoporosis. Nevertheless, further clinical studies are necessary to confirm the osteo-protective effects of betablockers.

\section{Serotonin (5-OH tryptamine)}

Serotonin is synthetized from tryptamine in duodenum (in chromaffin cells) and in the brain under the catalytic action of Tph1 and Tph2 enzymes, respectively. A very small amount of serotonin is also synthetized in bone tissue; both sources of serotonin have been shown to regulate bone remodeling. Brain-derived serotonin inhibits bone resorption (via sympathicus), stimulates proliferation of osteoblasts and increases bone formation, while duodenum-derived serotonin has the opposite effects. Furthermore, the well-known osteo-anabolic effect of Lrp5 could be partly explained by inhibition of the gut-derived serotonin (Yadav and Ducy 2010). As the crucial molecular node responsible for action of duodenal serotonin on osteoblast transcription complex FOXO1, working through cAMP and factor AFT4 has been identified in osteoblasts (Kode et al. 2012).

The opposite actions of serotonin (just described) have been demonstrated in genetically modified mice. While Tph1 deleted animals (with low duodenal and circulating serotonin values) expressed moderately higher bone density, Tph2 deleted animals (with a deficit of brain-derived serotonin) had low bone density (Kawai and Rosen 2004).

A negative relationship between serum serotonin levels and bone density/quality has also been shown in certain clinical studies. Low bone mass of the hip and a high risk of osteoporotic fractures have been observed in patients treated with some antipsychotic drugs, e.g. serotonin reuptake inhibitors (SSRIs) (Diem et al. 2007, Verdel et al. 2010) A recent retrospective review, which collected data from adolescents with eating disorders, over an 11 year period, found that SSRIs users had significantly lower bone mineral density (BMD) z-scores than control subjects (Corturier et al. 2013). These 
observations could be partly explained by serotonin transporters, which are expressed in bone tissue (Chen et al. 2012). From a practical point of view, patients with osteoporosis or history of low-energy fractures should be cautioned about the osteo-risks of SSRI (Sansone and Sansone 2012). Theoretically, molecular inhibition of duodenum-derived serotonin and simultaneous stimulation of brain-derived serotonin would be promising from the point of bone health (Karsenty and Yadav 2011).

Serotonin is a precursor of melatonin. This indol inhibits osteoclasts in vitro, but does not influence bone formation. Pharmacological doses of melatonin have been shown to decrease the number of osteoclasts by $76 \%$. Furthermore, melatonin increases bone volume by $49 \%$ and trabecular thickness by $19 \%$ (Koyama et al. 2003). Relevant clinical studies examining the effect of melatonin on the skeleton are still missing.

\section{Cannabinoids}

The main function of cannabinoids is regulation of food intake and energy balance. However, cannabinoids also regulate bone metabolism. Sources of endogenous molecules, such as anandamide and 2-arachidonolglycerol, have been found in both brain and bone tissue. After binding to specific G-proteins coupled receptors (CB1, CB2 and CPR55) located on cell membranes of osteoblasts and osteoclasts, cannabinoids modulate the activity of these cells through cAMP, NFkB, and kinases, e.g. MAPK (Idris and Ralston 2010). While CB1 receptors (encoded by the CNR1 gene) are present mainly in skeletal sympathetic nerve terminals, CB2 receptors (encoded by the CNR2 gene) are expressed in and modulate differentiation of osteoblasts, osteoclasts, osteocytes and bone marrow adipocytes (Idris and Ralston 2010, 2012, Whyte et al. 2012). Stimulation of CB1 has been shown to slow development of bone mass, but to increases bone volume in older age. Deficiency in CB1 stimulates bone development; however, it accelerates bone loss in older age. Other effects on the aging skeleton have also been observed with regard to the $\mathrm{CB} 2$ system, which inhibits bone resorption and slows bone loss in elderly subjects, while having no effect on the development of peak bone mass. In other words, agonists of $\mathrm{CB} 1$ or $\mathrm{CB} 2$ receptors have unambiguous osteo-protective effects relative to the aging skeleton, while the effects on bone development is either inhibitory, or missing. Activated CPR55 receptors, on the other hand, increase osteoclastic resorption and accelerate bone loss (Idris and Ralston 2012).

Data concerning the action of endogenouscannabinoids on the human skeleton are limited. Nevertheless, in humans, polymorphisms in the CNR2 gene, which encode the expression of cannabinoid receptors, were strongly associated with postmenopausal osteoporosis (Bab et al. 2012). Whether endogenous cannabinoids or synthetic cannabinoids can be used for the treatment of postmenopausal or senile osteoporosis is being extensively studied.

\section{Neuropeptide Y (NPY)}

NPY is produced in the hypothalamus, as well as in peripheral tissues, such as sympathetic nervous system, vasculature tissue, osteoblasts and osteocytes (Matic et al. 2012). Over-production of NPY directly modulates bone remodeling and affects coordinated interactions between fat and bone tissue (Shi and Baldock 2012). Relays from the hypothalamus to the skeleton acts through specific G-protein-coupled receptors located on osteoblasts (Y1 receptors) (Khor and Baldock 2012). Continuous production of NPY slows formation of endosteal and periosteal bone mass and accelerates loss of trabecular bone (Franguinho et al. 2010). Inhibition of NPY or deletion in Y1 receptor gene have been shown to increase cancellous bone volume in the femurs of mice and to quicken fracture healing (Lee et al. 2011, Sousa et al. 2013). Some anti-osteogenic effect has also been shown in activated Y2 receptors on hypothalamic NPY expressing neurons. However, Y2 receptors in mice regulated trabecular bone but not cortical bone (Shi et al. 2010).

Bone mass or architecture are in great part a result of changes in physical loading which works via mechanostat (Skerry 2008). Thus activated antiobesogenic hormone NPY negatively modulates bone parameters via loss of body weight. Moreover, NPY is also a critical modulator of the osteotropic effects associated with leptin (Gordeladze and Reseland 2003). Reduced serum leptin or leptin resistance, which occurs in obese subjects, could decrease cortical bone formation through activation of central NPY production (Wong et al. 2013).

Negative osteotropic effects have also been observed in anorexigenic neuromedin U. This peptide inhibits osteoblastic function and bone development in growing organisms. Accelerated bone formation was 
observed in mice with a deletion in the neuromedin gene (Nmu-/-) (Sato et al. 2007). Neuromedin U, like NPY, mediates the negative effects of leptin on bone (Sato et al. 2007). Pharmaceuticals that inhibit NPY and/or neuromedin $\mathrm{U}$ could potentially be used in the treatment of osteoporosis.

\section{Hormones of hypophysis}

Adenopituitary hormones, such as thyrotropin, follicle stimulating hormone and adrenocorticotropin (TSH, FSH and ACTH) regulate serum levels of thyroid hormones, estrogen and steroid hormones, respectively. Recently these glycoproteins have been shown to significantly modulate bone resorption and bone formation (Imam et al. 2009, Takeuchi 2013). It is known that TSH or agonists of TSH receptors (TSHR) inhibit osteoclastogenesis (Ma et al. 2011). In oophorectomized rats, TSH given intermittently, restores bone mineral density, micro-architecture and bone strength (Sampath et al. 2007). On the other hand, deletion in the TSHR gene leads to severe osteoporosis in mice, independently of thyroid hormone (Sendak et al. 2007). The results of cross-over study that showed a negative correlation between serum thyrotropin levels and certain indices of bone resorption (Zofkova and Hill 2008) support the above observations. The hypothesis of direct association between TSH and the skeleton was also supported by a controlled prospective study, in which suppressive doses of thyroxine in thyroidectomized postmenopausal women with papillary carcinoma, induced a decline in bone density (Sugitani and Fujimoto 2011). Nevertheless, it should be noted, that a positive association between circulating TSH and bone density in vivo can be confounded by actual thyroid hormone levels.

Osteo-protective effects have also been observed with ACTH. This peptide, in high concentrations, activates collagen I mRNK and through melanocortin receptors $(\mathrm{MC} 2 \mathrm{R})$ stimulates osteoblastic proliferation and bone formation. The low ACTH levels have the opposite effect (Isales et al. 2010). On the other hand, FSH activated interleukins (IL-1 beta), increased osteoresorption and unambiguously accelerated bone loss (Cannon et al. 2010).

Osteotropic effects of adenohypophyseal hormones have pathophysiologial impacts. Suppressed thyrotropin levels in patients with hyperthyreosis further accelerate bone resorption induced by high serum triiodothyronine. Similarly, bone resorption activated due to peripheral hypogonadism can be further potentiated by high FSH levels. More data from clinical studies are necessary to confirm the effect of synthetic adenohypophyseal hormones on bone remodeling.

Recently, it has been shown that oxytocin, a hormone produced in the neurohypophysis and also by osteoblasts, is involved in bone metabolism (Takeuchi 2013). It up-regulates osteoblast differentiation and production of bone morphogenetic peptide (BMP)-2. The absence of oxytocin receptors on osteoblasts inhibits estrogen-dependent differentiation of osteoblasts. In other words, oxytocin synthetized in bone mediates the osteoanabolic action of estrogen (Colaianni et al. 2012).

Lower oxytocin levels have been found in postmenopausal women with osteoporosis compared nonosteoporotic women (Breuil et al. 2011). Low oxytocin levels have also been observed in athletes (Lawson et al. 2013) and in girls with anorexia nervosa (Lawson et al. 2011). Although a causal association between low bone mass and low oxytocin levels has not been confirmed, results of the above mentioned studies foretell the hypothesis, which would be that oxytocin insufficiency has a causal role in osteoporosis seen in the above mentioned groups.

\section{Leptin}

Direct bone anabolic effects have been demonstrated in adipose-derived leptin. A number of in vitro studies have shown that leptin increases proliferation of osteoblasts and inhibits differentiation of bone marrow stromal cells into adipocytes. However, in vivo analyses have indicated that leptin also influenced bone mass indirectly through neuro-humoral pathways (Motyl and Rosen 2012). Leptin activates bone formation via beta-1-adrenergic receptors and activation of the somatotropin-IGF-1 system (Hamrick and Ferrari 2008). Through hypothalamic relays, leptin inhibits activity of oste-catabolic NPY (see above) and stimulates activity of osteo-anabolic systems, such as cocain and amphetamineregulating transcript (Kristensen et al. 1998). Additionally, leptin suppresses bone formation through beta-2-adrenergic receptors located in bone and inhibits serotonin synthesis in the brain, the consequence of which is loss of trabecular bone formation (Motyl and Rosen 2012). Therefore, the final effect of leptin on the skeleton depends on the balance between anabolic and catabolic activities. The role of these mechanisms, in the acquisition of peak bone mass and/or maintenance of 
adult skeleton mass, remains to be determined.

\section{Conclusion}

The brain regulates bone metabolism via a number of humoral systems expressed in the hypothalamus and hypophysis. The objective of neuroskeletal biology is synthesis of new molecules with inhibitory effects on beta-2-adrenergic system, NPY and neuromedin $U$ or drugs which stimulate synthesis of cannabinoids and brain variants of serotonin. Potential osteo-protective pharmaceuticals could also be recombinant molecules of oxytocin and $\mathrm{ACTH}$, as well as synthetic agonist of thyrotropin receptors. Finally, it is noteworthy that this review identified SSRI as drugs that can be potentially harmful to the skeleton.

\section{Conflict of Interest}

There is no conflict of interest.

\section{Acknowledgements}

This work was supported by the project (Ministry of Health, Czech Republic) for conceptual development of research organization 00023761 (Institute of Endocrinology, Prague, Czech Republic).

\section{References}

ARAI M, NAGASAWA T, KOSHIHARA Y, YAMAMOTO S, TAGARI A: Effects of beta-adrenergic agonists on bone-resorbing activity in human osteoclast-like cells. Biochim Biophys Acta 1640: 137-142, 2003.

BAB I, ZIMMER A, MELAMED E: Cannabinoids and the skeleton: from mariujana to reversal of bone loss. Ann Med 41: 560-567, 2009.

BONNET N, PIERROZ DD, FERRARI SL: Adrenergic control of bone remodeling and its implications for the treatment of osteoporosis. J Musculoskelet Neuronal Interact 8: 94-104, 2008.

BREUIL V, AMRI EZ, PANAIA-FERRARI P, TESTA J, ELABD C, ALBERT-SABOUNADIERE C, ROUX CH, AILHAUD G, DANI C, CARLE GF, EULLER-ZIEGLER L: Oxytocin and bone remodelling: Relationships with neuropituitary hormones, bone status and body composition. Point Bone Spin 78: 611-615, 2011.

CANNON JG, CORTEZ-COOPER M, MEADERS E, STALLINGS J, HADDOW S, KRAJ B, SLOAN G, MULLOY A: Follicle-stimulating hormone, interleukin-1, and bone density in adult women. Am J Physiol Regul Integr Comp Physiol 298: R790-R798, 2010.

CHEN F, HAHN TJ, WEINTRAUB NT: Do SSRIs play a role in decreasing bone mineral density? J Am Med Dir Assoc 13: 413-417, 2012.

COLAIANNI G, SUN L, Di BENEDETTO A, TAMMA R, ZHU LL, CAO J, GRANO M, YUEN T, COLUCCI S, CUSCITO C, MANCINI L, LI J, NISHIMORI K, BAB I, LEE HD, IQBAL J, YOUNG WS 3RD, ROSEN C, ZALLONE A, ZAIDI M: Bone marrow oxytocin mediates the anabolic action of estrogen on the skeleton. J Biol Chem 287: 29159-29167, 2012.

CORTURIER J, SY A, JOHNSON N, FINDLAY S: Bone mineral density in adolescents with eating disorders exposed to selective serotonin reuptake inhibitors. Eat Disord 21: 238-248, 2013.

DE VRIES F, POUWELS S, BRADLE M, LEUFKENS HG, COOPER C, LAMMERS JW, VAN STAA TP: Use of beta-2 agonists and risk of hip/femur fracture: a population-based case-control study. Pharmacoepidemiol Drug Saf 16: 612-619, 2007.

DIEM SJ, BLACKWELL TL, STONE KL, YAFFE K, HANEY EM, BLIZIOTES MM, ENSRUD KE: Use of antidepresants and rates of hip bone loss in older women: the study of osteoporotic fractures. Arch Intern Med 167: 1240-1245, 2007.

DRIESSLER F, BALDOCK PA: Hypothalamic regulation of bone. J Mol Endocrinol 45: 175-181, 2010.

ELEFTERIOU F, AHN JD, TAKEDA S, STARBUCK M, YANG X, LIU X, KONDO H, RICHARDS WG, BANNOU TW, NODA M, CLEMENT K, VAISSE C, KARSENTY G: Leptin regulation of bone resorption by the sympathetic nervous system and CART. Nature 434: 514-520, 2005.

ELEFTERIOU F, CAMPBELL P, MA Y: Control of bone remodeling by the peripheral sympathetic nervous system. Calcif Tissue Int 94: 140-151, 2014. 
FARR JN, CHARKOUDIAN N, BARNES JN, MONROE DG, MCCREADY LK, ATKINSON EJ, AMIN S, MELTON LJ 3RD, JOYNER MJ, KHOLA S: Relationship of sympathetic activity to bone microstructure, turnover, and plasma osteopontin levels in women. J Clin Endocrinol Metab 97: 4219-4227, 2012.

FRANGUINHO F, LIZ MA, NUNES AF, NETO E, LAMGHARI M, SOUSA MM: Neuropeptide Y and osteoblast differentiation-the balance between the neuro-osteogenic network and local control. FEBS J 277: 3664-3667, 2010.

GORDELADZE JO, RESELAND JE: A unified model for the action of leptin on bone turnover. J Cell Biochem 88: 706-712, 2003.

GRADOSOVA I, ZIVNA H, ZIVNY P: Influence of metoprolol on bone metabolism in male Wistar rats after oophorectomy (in Czech). Osteological Bulletin 16: 132-136, 2011.

HAMRICK MW, FERRARI SL: Leptin and the sympathetic connection of fat to bone. Osteoporosis Int 19: 905-912, 2008.

IDRIS AI, RALSTON SH: Cannabinoids and bone: friend or foe? Calcif Tissue Int 87: 285-297, 2010.

IDRIS AI, RALSTON SH: Role of cannabinoids in the regulation of bone remodeling. Front Endocrinol (Lausanne) 3 : $136,2012$.

IMAM A, IQBAR J, BLAIR HC: Role of the pituitary-bone axis in skeletal pathophysiology. Opin Endocrinol Diabetes Obes 16: 423-429, 2009.

ISALES CM, ZAIDI M, BLAIR HC: ACTH is a novel regulator of bone mass. Ann NY Acad Sci 1192: 110-116, 2010.

KARSENTY G, YADAV VK: Regulation of bone mass by serotonin: molecular biology and therapeutic implications. Annu Rev Med 62: 323-331, 2011.

KAWAI M, ROSEN CJ: Minireview: A skeleton in serotonin's closet? Endocrinology 151: 4103-4108. 2010.

KHOR EC, BALDOCK P: The NPY system and its neural and neuroendocrine regulation of bone. Curr Osteoporos Rep 10: 160-168, 2010.

KODE A, MOSIALOU I, SILVA BC, RACHED MT, ZHOU B, WANG J, TOWNES TM, HEN R, DEPINHO RA, GUO XE, KOUSTENI S: FOXO1 orchestrates the bone-suppressing function of gut-derived serotonin. $J$ Clin Invest 122: 3490-3503, 2012.

KONDO A, TOVARU A: In vivo stimulation of sympathetic nervous system modulates osteoblastic activity in mouse calvaria. Am J Physiol Endocrinol Metab 285: E661-E667, 2003.

KOYAMA H, NAKADE O, TAKADA Y, KAKU T, LAU KH: Melatonin at pharmacologic doses increases bone mass by suppressing resorption through down-regulation of the RANKL-mediated osteoklast formationand activation. J Bone Miner Res 17: 1219-1229, 2002.

KRISTENSEN P, JUDGE ME, THIM L, RIBEL U, CHRISTJANSEN KN, WULFF BS, CLAUSEN JT, JENSEN PB, MADSEN OD, VRANG N, LARSEN PJ, HASTRUP S: Hypothalamic CART is a new anorectic peptide regulated by leptin. Nature 393: 72-76, 1998.

LAWSON EA, ACKERMAN KE, ESTELLA NM, GUERECA G, PIERCE L, SLUSS PM, BOUXEIN ML, KLIBANSKI A, MISRA M: Nocturnal oxytocin secretion is lower in amenorrheic athletes than nonathletes and associated with bone microarchitecture and finite element analysis parameters. Eur J Endocrinol 168: 457-464, 2013.

LAWSON EA, DONOHO DA, BLUM JI, MANAGHAN EM, MISRA M, HERZOG DB, SLUSS PM, MILLER KK, KLIBANSKI A: Decreased nocturnal oxytocin levels in anorexia nervosa are associated with low bone mineral density and fat mass. J Clin Psychiatry 72: 1546-1551, 2011.

LEE NJ, NGUYEN AD, ENRIQUEZ RE, DOVLE KL, SAINSBURY A, BLADOCK PA, HERZOG H: Osteoblast specific Y1 receptor deletion enhances bone mass. Bone 48: 461-467, 2011.

MA R, MORSHED S, LATIF R, ZAIDI M, DAVIES TF: The influence of thyroid-stimulating hormone and thyroidstimulating hormone receptor antibodies on osteoclastogenesis. Thyroid 21: 897-906, 2011.

MASI L: Crosstalk between the brain and bone. Clin Cases Bone Metab 9: 13-16, 2012.

MATIC I, MATTHEWS BG, KIZIVAT T, IQWE JC, MARIJANOVIC I, RUOHONEN ST, SAVONTAUS E, ADAMS DJ, KALAJZIC I: Bone-specific overexpression of NPY modulates osteogenesis. $J$ Musculoskelet Neuronal Interact 12: 209-218, 2012. 
MINKOWITZ B, BOSKEY AL, LANE JM, PEARLMAN HS, VIGORITA VJ: Effects or propranolol on bone metabolism in the rat. J Orthop Res 9: 869-875, 1991.

MOTYL KJ, ROSEN CJ: Understanding leptin-dependent regulation of skeletal homeostasis. Biochemie 94: 20892096, 2012.

PASCO JA, HENRY MJ, SANDERS KM, KOTOWICZ MA, SEEMAN E, NICHOLSON GC: Beta-adrenergic blockers reduce the risk of fracture partly by increasing bone mineral density: Geelong Osteoporosis Study. J Bone Miner Res 19: 19-24, 2004.

SAMPATH TK, SIMIC P, SENDAK R, DRACA N, BOWE AE, O'BRIEN S, SCHIAVI SC, MCPHERSON JM, VUKICEVIC S: Thyroid-stimulating hormone restores bone volume, microarchitecture, and strength in aged ovariectomized rats. J Bone Miner Res 22: 849-859, 2007.

SANSONE RA, SANSONE LA: SSRIs: bad to the bone? Innov Clin Neurosci 9: 42-47, 2012.

SATO S, HANADA R, KIMURA A, ABE T, MATSUMOTO T, IWASAKI M, INOSE H, IDA T, MIEDA M, TAKEUCHI Y, FUKUMOTO S, FUJITA T, KATO S, KANGAWA K, KOJIMA M, SHINOMIYA K, TAKEDA S: Central control of bone remodeling by neuromedin U. Nat Med 13: 1234-1240, 2007.

SCHLIENGER RG, KRAENZIN ME, JICH SS, MEIER CR: Use of beta-blocker and risk of fractures. JAMA 292: 1326-1332, 2004.

SENDAK RA, SAMPATH K, MCPHERSON JM: Newly reported roles of thyroid-stimulating hormone and folliclestimulating hormone in bone remodelling. Int Orthop 31: 753-757, 2007.

SHI YC, BALDOCK PA: Central and peripheral mechanisms of the NPY system in the regulation of bone and adipose tissue. Bone 50: 430-436, 2012.

SHI YC, LIN S, WONG IP, BALDOCK PA, ALJANOVA A, ENRIGUEZ RF, CASTILLO L, MITCHELL NF, YE JM, ZHANG L, MACIA L, YULVANINGSIH E, NGUYEN AD, RIEPLER SJ, HERZOG H, SAINSBURY A: NPY neuron-specific Y2 receptors regulate adipose tissue and trabecular bone but not cortical bone homeostasis in mice. PLoS One 5: e11361, 2010.

SOUSA DM, MCDONALD MM, MIKULEC K, PEACOCK, HERZOG H, LAMGHARI M, LITTLE DG, BALDOCK PA: Neuropeptide Y modulates fracture healing through Y1 receptor signaling. J Orthop Res 31: 1570-1578, 2013.

SUGITANI I, FUJIMOTO Y: Effect of postoperative thyrotropin suppressive therapy on bone mineral density in patients with papillary thyroid carcinoma: a prospective controlled study. Surgery 150: 1250-1257, 2011.

TAKEUCHI Y: Possible involvement of pituitary hormones in bone metabolism. Clin Calcium 23: 195-205, 2013.

VERDEL BM, SOUVEREIN PC, EGBERTS TC, VAN STAA TP, LEUFKENS HG, DE VRIES F: Use of antidepressant drugs and risk of osteoporotic and non-osteoporotic fractures. Bone 47: 604-609, 2010.

WHYTE LS, FORD L, RIDGE SA, CAMERON GA, ROGERS MJ, ROSS RA: Cannabinoids and bone: endocannabinoids modulate human osteoclast function in vitro. Br J Pharmacol 165: 2584-2597, 2012.

WONG IP, NGUEN AD, KHOR EC, ENRIGUEZ RF, EISMAN JA, SAINSBURY A, HERZOG H, BALDOCK PA: Neuropeptide $\mathrm{Y}$ is a critical modulator of leptin's regulation of cortical bone. $J$ Bone Miner Res 28: 886-898, 2013.

YADAV VK, DUCY P: Lrp5 and bone formation: a serotonin-dependent pathway. Ann NY Acad Sci 1192: 103-109, 2010.

ZOFKOVA I, HILL M: Biochemical markers of bone remodeling correlate negatively with circulating TSH in postmenopausal women. Endocr Regul 42: 121-127, 2008. 